\title{
FACTORS AFFECTING DELIVERY CARE OF URBAN MOTHERS: A CROSS- SECTIONAL STUDY OF THE URBAN PRIMARY HEALTH CARE PROJECT IN BANGLADESH
}

\author{
Sharmin Mizan ${ }^{1}$, Md Mizanur Rahman ${ }^{1 *}$,Razitasham Safii ${ }^{1}$, Sk Akhtar Ahmad ${ }^{2}$ \\ ${ }^{1}$ Faculty of Medicine and Health Sciences, Universiti Malaysia Sarawak, Malaysia \\ ${ }^{2}$ Faculty of Public Health, Bangladesh University of Health Sciences, Bangladesh \\ *Correspondence: Md Mizanur Rahman, email: rmmizanur@unimas.my
}

\begin{abstract}
Maternal mortality and its associated complications can be avoided by ensuring safe and supervised delivery. In this paper, the authors examined the factors associated with the utilisation of institutional delivery care at the Urban Primary Health Care Project (UPHCP) clinic in Bangladesh. A two-stage cluster sampling was used in selecting the evermarried women aged 15-49 years in the catchment areas of the UPHCP in Bangladesh. A total of 3,949 women's data were analysed. The authors collected data through face-to-face interviews using a structured questionnaire. A multinomial logistic regression analysis was done to determine the potential factors associated with the utilisation of delivery care, in which 'place of delivery care' was considered as a dependent variable. Data entry and analysis were done in Statistical Package for the Social Sciences version 22.0. This study found that 30\% of the women delivered their most recent child at the UPHCP clinic, and $45.9 \%$ of the women delivered their most recent child at other institutions. However, one-fifth of the women delivered at home. Doctors attended two-thirds of the deliveries. A small proportion of women were tended to by nurses, paramedics, FWV, and FWA. Traditional birth attendants attended one-fifth (20\%) of deliveries. The multinomial logistic regression analysis found that respondents from poor catchment areas were 33.677 times more likely to utilise delivery care at the UPHCP when compared to 12.052 times by the respondents who took previous antenatal care from the non-poor catchment area. This study also found that women who had entitlement cards were 6.840 times more likely to utilise delivery care at the UPHCP in the poor catchment area, which was almost twice the women from the non-poor catchment area. Although the maternal mortality rate in Bangladesh has notably reduced,Bangladesh still needs to address the issue of safe delivery for marginalised women in order to attain the Sustainable Development Goals (SDGs) by 2030. A red card approach might increase access to the UPHCP for marginalised women to have safe deliveries.
\end{abstract}

Keywords: poor, urban, red card, delivery care, Urban Primary Health Care Project, Bangladesh

\section{INTRODUCTION}

Significant landmarks and instruments were constructed between the Safe Motherhood Conference in 1987 and the Millennium Development Goals(MDGs) announcement in 2000, where maternal mortality was recognised and conferred as a concern in oviding major technical and political forces to achieve good maternal health (Alkema et al., 2016). The critical issue is that there are approximately 210 million pregnancies per year, and about 140 million babies are born annually. Any pregnancy reaching the labour stage may be complicated, and this is the stage during which most maternal deaths occur. Undesired maternal death could be avoided by delivering in a safe, clean environment with the supervision of health professionals. Comprehension of the maternal health program is needed to address maternal wellbeing and her existence (Smith et al., 2011).

An amazing personal experience of a woman is pregnancy. Nobody does know the time of the progress of labour, complications, and what passions one will go 
through during the process of childbirth. MDGs were replaced by the Sustainable Development Goals (SDGs) in 2015, which had targeted global aternal mortality ratio of less than 70 in 100,000 live births by 2030 (WHO, 2015) has stated that satisfactory effort should be given until no single country has an MMR exceeding 140 maternal deaths per 100,000 live births. The relative socioeconomic and cultural environment women grow up in has influenced them to modify their preference in selecting childbirth locations. Partial determinants are available opportunities, potentialities, and constraints on the recognition of wishes of the mothers were to deliver their baby (Tuladhar, 2009). According to the Bangladesh Bureau Statistics (2015), most maternal deaths occurred due to delivery complications. Productive and reproductive activities are loaded upon a woman as a double burden, in addition to other familial responsibilitiesand social works (WHO, 2006).

In 1998, the government of Bangladesh implemented the Urban Primary Health Care Project (UPHCP) utilising a Public-Private Partnership (PPP) model to provide primary health care services, particularly maternal and child health services, to the urban poor. Ten city corporations and four selected municipalities of Bangladesh operate the UPHCP clinic. Entitlement cards (i.e. red cards) were distributed to poor households to provide free maternal and child healthcare services (LGRDC, 2012).

The main aim of the study was to determine the prevalence of utilisation of delivery care and its associated factors delivered at the UPHCP clinics.

\section{METHODS}

\section{Setting, sampling, and population}

The authors conducted a crosssectional study in the Urban Primary Health
Care Clinic (UPHCC) project area. Data were collected from women aged 15-49 years with at least one child aged less than two years through a two-stage cluster sampling technique. The authors analysed 3,949 completed data with a response rate of about 97\%. The authors excluded (a) any visitor or guest residing in the household; (b) those who did not give consent or were unwilling to participate; (c) failure to interview after three attempts. The mean (SD) age of the respondents was 25.49 (51 years). The majority of women observed $(90.4 \%)$ were Muslim. The median family size was four. More than one-third of women had completed their primary education (38.2\%), followed by $32.0 \%$ who had completed a secondary level of education. The majority of the women (83.1\%) were housewives. Regarding their husband's occupations, more than one-fourth of their husbands (27.3\%) engaged in business. The median family income was BDT 12,000. One-fourth (25.2\%) of households had an entitlement card that was provided by the UPHCP.

\section{Data collection}

The authors developed a data collection instrument based on several previous studies (Bhardwaj et al., 1995; NIPORT, 2013; Rahman, 1997). The questionnaire consisted of several sections. The first section was the socio-economic characteristics, followed by the utilisation, satisfaction, quality of life, and willingness to pay for $\mathrm{MCH}$ services. In this paper, the authors analysed the usage of delivery care services at the UPHCP clinic. Data were collected through face-to-face interviews using the Bangla (mother tongue) version of the questionnaire. Before the actual survey, the authors conducted a pre-test in the nonsample area. Minor changes were made after the pre-testing of the questionnaire. The authors recruited trained research assistants for data collection. All the participants were 
briefed about the objectives of the study, and written informed consent was obtained prior to data collection.

\section{Data processing and analysis}

Completeness and inconsistencies in the collected data were checked manually. IBM SPSS version 22.0 (IBM SPSS, 2013) was used for data entry and analysis. Missing data examination and imputation were done with the help of SPSS. After validation, a descriptive analysis was done and its results were presented in frequency tables. A $\mathrm{m}$ ultinomial regression analysis was carried out to identify the prevalence of utilisation of delivery care and potential predictors, in which 'place of delivery care' was considered as a dependent variable.

\section{RESULTS}

\section{Delivery care}

Doctors attended the deliveries of two-thirds of the women during their latest delivery $(68 \%)$. Very few deliveries were attended by nurses $(6.6 \%)$ and paramedics $(4.2 \%)$. However, one-fifth of the women (20.3\%) had traditional birth attendants present. One-third of the women delivered their most recent child at the UPHCP clinic $(29.6 \%)$. The highest number of women $(45.9 \%)$ had institutional deliveries, such as at government hospitals, private hospitals/clinics, NGO clinics, and other health facilities. However, one-fourth of women $(24.6 \%)$ delivered at home. More than half of the women delivered natural birth their last child. Emergency operations and elective operations, such as Lower Uterine Caesarean Sections (LUCS), were done on $16.2 \%$ of women and one-tenth of the respondents $(10.9 \%)$, respectively. $15.9 \%$ of respondents experienced assisted normal deliveries. The median amount of expenses for delivery was BDT 3,500 (Table 1).

Table 1. Characteristics of the delivery care

\begin{tabular}{|c|c|c|c|c|}
\hline \multirow[t]{2}{*}{ Variables } & \multirow[t]{2}{*}{ Frequency } & \multirow[t]{2}{*}{ Percentage } & \multicolumn{2}{|c|}{$95 \% C I$} \\
\hline & & & $\begin{array}{c}\text { Lower } \\
\text { limit }\end{array}$ & $\begin{array}{c}\text { Upper } \\
\text { limit }\end{array}$ \\
\hline \multicolumn{5}{|l|}{ Birth Attendant $(n=3767)$} \\
\hline Doctor & 2560 & 68.0 & 66.5 & 69.4 \\
\hline Paramedic & 160 & 4.2 & 3.6 & 4.9 \\
\hline Nurse & 249 & 6.6 & 5.9 & 7.4 \\
\hline FWV\& FWA & 35 & 1.0 & 0.5 & 1.4 \\
\hline Traditional birth attendant & 763 & 20.3 & 18.9 & 21.5 \\
\hline Place of delivery $(n=3949)$ & 85 & 2.3 & 1.7 & 3.0 \\
\hline UPHCP & 1167 & 29.6 & 28.2 & 31.0 \\
\hline Institutional & 1811 & 45.9 & 44.3 & 47.4 \\
\hline Home & 971 & 24.6 & 23.3 & 26.0 \\
\hline \multicolumn{5}{|l|}{ Type of delivery } \\
\hline Normal delivery & 2076 & 52.6 & 51.0 & 54.1 \\
\hline Assisted Normal delivery & 628 & 15.9 & 14.8 & 17.0 \\
\hline Instrumental delivery & 178 & 4.5 & 3.9 & 5.2 \\
\hline Elective operation & 429 & 10.9 & 9.9 & 11.8 \\
\hline Emergency operation & 638 & 16.2 & 15.0 & 17.3 \\
\hline \multicolumn{5}{|c|}{ Out of pocket expenses for Delivery (BDT) } \\
\hline Median out of pocket expenses & & BDT 3500 & BDT & BDT \\
\hline & & & 3000 & 4000 \\
\hline
\end{tabular}




\section{Factors affecting the utilisation of delivery care: multinomial regression analysis}

To determine the factors affecting the utilisation of delivery care, the authors conducted a stepwise multinomial logistic regression analysis. The dependent variable, place of delivery, was polytomous, which categorised into Urban Primary Health Care Clinic (UPHCC), institutional delivery, which was other than UPHCC, including government, private, and NGOs, and last category was home delivery. Home delivery was considered as the reference category.

In the authors' analysis, variables such as religion, level of education, occupation, husband's occupation, history of loan, red card status, wealth index, and age in years were included in the model. The authors removed family income and family size due to multicollinearity. The delivery and previous antenatal care variables were then entered into the model. In the second stage, birth weight and prior history of antenatal care were retained. Stratified analysis indicated that age, religion, respondents' occupation, their husbands' occupation, red card status, and wealth index should be retained in the non-poor groups (Table 2), while the occupation of the respondents and their husbands was removed in the poor catchment category. Previous antenatal care and birth weight data were retained in the poor catchment area (Table 3). In contrast, recent history of antenatal care was retained in the non-poor catchment category. Finally, the authors examined the individual predictors and set a critical p-value of 0.007 to minimise the type I error (Bonferroni correction). The detailed model fitting this information is illustrated at the bottom of each table. The classification analysis showed that $62.2 \%$ of the cases were correctly classified into the non-poor group, whereas it was $67.6 \%$ in the poor group.

The analysis revealed that past antenatal care, wealth index, and red card status appeared to be highly significant predictors of the utilisation of delivery care. It was found that women from poor catchment areas were 33.677 times more likely to utilise the UPHCP clinic's delivery care, compared to 12.052 times by the respondents from the non-poor catchment area who received ANC previously. However, the utilisation of institutional deliveries by the women from poor catchment areas was slightly higher (Adj. OR= 5.18; 95\% CI: 3.48, 7.744) than the women from non-poor catchment areas (Adj. OR= 4.833; 95\% CI: 3.09, 7.55). Data showed that the utilization of institutional delivery was higher among the women from poor catchment areas $(\mathrm{Adj} . \mathrm{OR}=6.56 ; 95 \%$ $\mathrm{CI}=2.86,15.02)$ compared to non-poor catchment areas (Adj. $\mathrm{OR}=3.53 ; 95 \% \mathrm{CI}=$ $2.07,6.04$ ) among the women of the fifth quintile. It was also high among the respondents of the fifth quintile from both poor $($ Adj. $\mathrm{OR}=2.32 ; 95 \% \mathrm{CI}=1.53,3.52$ ) and non-poor catchments (Adj. OR= 2.21; $95 \% \mathrm{CI}=1.31,3.70)$. The women of the third quintile also utilised institutional delivery services from the poor group (Adj. $\mathrm{OR}=1.77$; $95 \% \mathrm{CI}=1.28,2.45)$. However, no other categories of wealth index appeared to be statistically significant $(\mathrm{p}>0.05)$ (Table 2 and Table 3). The utilisation of the UPHCP clinic was 6.84 times (95\% CI: 5.215, 8.971) higher among the women with entitlement cards in poor catchment areas compared to non-poor catchment areas (Adj. OR = 3.499; 95\% CI: 2.313, 5.293). However, the authors did not find any impact of the entitlement card for other institutional deliveries $(\mathrm{p}>$ $0.05)$. 
Table 2. Factors affecting the utilisation of delivery care: Multinomial regression analysis for non-poor catchment area

\begin{tabular}{|c|c|c|c|c|}
\hline \multirow[t]{3}{*}{ Variables } & \multicolumn{4}{|c|}{ Non-Poor } \\
\hline & \multicolumn{2}{|c|}{ UPHCP } & \multicolumn{2}{|c|}{ Institutional } \\
\hline & Adj.OR & $95 \% C I$ & Adj.OR & $95 \% C I$ \\
\hline Age in years & $1.045 * *$ & $(1.015,1.076)$ & 0.980 & $(0.956,1.006)$ \\
\hline \multicolumn{5}{|l|}{ Religion } \\
\hline Non-Muslim & 1.00 & & 1.00 & \\
\hline Muslim & 0.642 & $(0.352,1.170)$ & $0.374 * * *$ & $(0.224,0.625)$ \\
\hline \multicolumn{5}{|c|}{ Occupation (respondent) } \\
\hline Not working & 1.401 & $(0.638,3.079)$ & 1.533 & $(0.790,2.978)$ \\
\hline Working & $2.708 * * *$ & $(1.639,4.475)$ & 1.686 & $(1.047,2.716)$ \\
\hline Housewife & 1.00 & & 1.00 & \\
\hline \multicolumn{5}{|c|}{ Occupation (Husband) } \\
\hline Small trade & 1.737 & $(0.788,3.828)$ & $4.093 * * *$ & $(1.968,8.511)$ \\
\hline Service & 1.871 & $(0.850,4.118)$ & $2.890 * *$ & $(1.384,6.034)$ \\
\hline Manual job & 1.313 & $(0.599,2.876)$ & 2.295 & $(1.102,4.777)$ \\
\hline No specific job & 1.00 & & 1.00 & \\
\hline \multicolumn{5}{|l|}{ Having a Red Card } \\
\hline Yes & $3.499 * * *$ & $(2.313,5.293)$ & 0.992 & $(0.653,1.507)$ \\
\hline No & 1.00 & & 1.00 & \\
\hline \multicolumn{5}{|l|}{ Wealth Index } \\
\hline $5^{\text {th }}$ quintile & 1.045 & $(0.590,1.852)$ & $3.532 * * *$ & $(2.078,6.004)$ \\
\hline $4^{\text {th }}$ quintile & 0.888 & $(0.509,1.550)$ & $2.211^{* *}$ & $(1.318,3.707)$ \\
\hline $3^{\text {rd }}$ quintile & 0.811 & $(0.458,1.436)$ & 1.473 & $(0.867,2.500)$ \\
\hline $2^{\text {nd }}$ quintile & 0.785 & $(0.438,1.409)$ & 0.877 & $(0.501,1.534)$ \\
\hline $1^{\text {st }}$ quintile & 1.00 & & 1.00 & \\
\hline \multicolumn{5}{|l|}{ ANC last visit } \\
\hline Yes & $12.052 * * *$ & $(5.089,28.543)$ & $4.833 * * *$ & $(3.093,7.553)$ \\
\hline No & 1.00 & & 1.00 & \\
\hline Intercept & $3.632 * * *$ & & -0.839 & \\
\hline Sample size & \multicolumn{4}{|c|}{1985} \\
\hline Model fitting & \multicolumn{4}{|c|}{$\chi^{2}(d f)=414.796(26) ; p<0.001$} \\
\hline Goodness-of-Fit & \multicolumn{4}{|c|}{ Pearson $=3108.073(2894) ; p=0.003 ;$ Deviance $=2831.129(2894) ; p=0.795$} \\
\hline Pseudo R-Square & \multicolumn{4}{|c|}{ Cox and Snell =0.189; Nagelkerke $=0.220$} \\
\hline Reference & \multicolumn{4}{|c|}{ Home delivery } \\
\hline
\end{tabular}


Table 3. Factors affecting the utilisation of delivery care: Multinomial regression analysis for poor catchment area

\begin{tabular}{|c|c|c|c|c|}
\hline \multirow[t]{3}{*}{ Variables } & \multicolumn{4}{|c|}{ Poor } \\
\hline & \multicolumn{2}{|c|}{ UPHCP } & \multicolumn{2}{|c|}{ Institutional } \\
\hline & Adj.OR & $95 \% C I$ & Adj.OR & $95 \% C I$ \\
\hline Age in years & $1.050 * * *$ & $(1.025,1.077)$ & 0.995 & $(0.972,1.019)$ \\
\hline \multicolumn{5}{|l|}{ Having a Red Card } \\
\hline Yes & $6.840 * * *$ & $(5.215,8.971)$ & 0.933 & $(0.700,1.244)$ \\
\hline No & 1.00 & & 1.00 & \\
\hline \multicolumn{5}{|l|}{ Wealth Index } \\
\hline $5^{\text {th }}$ quintile & $4.597 * *$ & $(1.886,11.208)$ & $6.559 * * *$ & $(2.863,15.026)$ \\
\hline $4^{\text {th }}$ quintile & 1.708 & $(1.073,2.718)$ & $2.319 * * *$ & $(1.527,3.524)$ \\
\hline $3^{\text {rd }}$ quintile & 1.453 & $(1.023,2.063)$ & $1.772 * * *$ & $(1.282,2.450)$ \\
\hline $2^{\text {nd }}$ quintile & 1.085 & $(.796,1.480)$ & 1.323 & $(0.985,1.776)$ \\
\hline $1^{\text {st }}$ quintile & 1.00 & & 1.00 & \\
\hline \multicolumn{5}{|l|}{ ANC last visit } \\
\hline Yes & $33.677 * * *$ & $(12.120,93.57)$ & $5.180 * * *$ & $(3.467,7.740)$ \\
\hline No & 1.00 & & 1.00 & \\
\hline \multirow[t]{2}{*}{ Birth weight(kg) } & & NI & & \\
\hline & 1.292 & $(1.006,1.661)$ & $1.400 * *$ & $(1.112,1.763)$ \\
\hline Intercept & $-6.371 * * *$ & & $-1.861 * *$ & \\
\hline Sample size & \multicolumn{4}{|c|}{1964} \\
\hline Model fitting & \multicolumn{4}{|c|}{$\chi^{2}(d f)=699.044(18) ; p<0.000$} \\
\hline Goodness-of-Fit & \multicolumn{4}{|c|}{$\begin{array}{l}\text { Pearson }=3145.482(3092) ; p=0.247 \\
\text { Deviance }=2951.135(3092) ; p=0.965)\end{array}$} \\
\hline Pseudo R-Square & \multicolumn{4}{|c|}{ Cox and Snell=0.299; Nagelkerke $=0.337$} \\
\hline
\end{tabular}

\section{DISCUSSION}

To reduce maternal mortality and neonatal mortality, delivery assisted by a trained medical provider is an important factor. The Bangladesh Demographic Health Survey (2014) reported that in urban areas, delivery attended by qualified doctors was also high than other providers who are similar to this study (NIPORT, 2016). In some developing countries in South East Asia and Sub-Saharan Africa, cultural and societal norms are significant determinants for the place of delivery, and lead to high numbers of home deliveries. The present study finding was higher than those by the BDHS (2014) regarding delivery in a health facility $(56.8 \%)$ in urban areas One BDHS finding was similar to the present study where delivery at the UPHCP was $28.5 \%$ and home delivery $43.9 \%$ (HB Consultants and Natural Resources Planners, 2012). Results from the BDHS (2014) revealed that $23 \%$ of all births were done via $\mathrm{C}$-section, and in urban areas, it was 38\% (NIPORT, 2016). The BDHS (2014) found more C-section deliveries in urban areas than the present study did. Rahman et al. (2012) reported that women in Bangladesh paid 1.5 times more for by normal (USD 42.30) and cesarean deliveries (USD136.20) at private health facilities compared to public health facilities. In this present study, out-of-pocket (OOP) expenditure was not desegregated according to the mode of delivery. On average, OOP expenditure seemed slightly higher in 
comparison to the previous study by Rahman et al. (2012). In Bangladesh, three-fifths $(62 \%)$ of women delivered at home, despite $78 \%$ of women receiving ANC at least once from a provider (NIPORT, 2016). However, our study found that three-fourths $(75.5 \%)$ of births were delivered at a health facility, and $24.6 \%$ were delivered at home, whereas $93 \%$ of all respondents received ANC from a provider. This may be due to the short distance between their residences and healthcare facilities. In Kenya, more than four-fifths $(88 \%)$ of mothers live less than five kilometers from a health facility, but the percentage of deliveries in health facilities is still not satisfactory. More than half (53\%) of deliveries take place outside of health facilities, and $93 \%$ of pregnant mothers have at least one ANC visit (Kitui et al., 2013). In Ethiopia, only $3 \%$ of women deliver their babies in health facilities, though the proportion of any ANC visit from a health professional among rural mothers in their most recent pregnancy is $25 \%$ (Eshete et al., 2019). From the above discussion, the nutshell is in the developing countries, delivery care at the health facility is still low compared to antenatal care by a health care provider. Lower rate of institutional/facility delivery is one of the reasons for maternal mortality and morbidity. 'Health-centre intrapartum care strategy' is a key strategy for reducing maternal and neonatal deaths (Campbell \& Graham, 2006). Qualified skilled workers, effective referral systems, and a useful postnatal care package are core components of this strategy to manage labour complications and refer for specialised care when needed (WHO, 2016; Kruk et al., 2018).

The analysis revealed that previous antenatal care, wealth index, and red card status appeared to be highly significant predictors of the utilisation of delivery care. Findings of this study are comparable to other developing countries where ANC utilisation, residence, catchment areas, and wealth have appeared as essential factors (Stephenson et al., 2006; Mrisho et al., 2007; Sabine Gabrysch \& Campbell, 2009; S. Gabrysch et al., 2011; Say et al., 2014). Women in wealthy households are more likely to deliver at proper health facilities. With the increasing wealth index, the pattern of delivery practices to be changed. Wealthier women prefer maternal health facilities over home deliveries (Fotso \& Mukiira, 2012; Goel et al., 2015). Clients' financial capability influences their usage of health services. Previous studies have shown the monetary incapability of a client has acted as a major barrier in utilising delivery care at health facilities (Kabia et al., 2019). Past studies in urban slums have reflected the same results (van der Heijden et al., 2019).

The authors hypothesised that the distribution of entitlement cards (red cards) among the slum dwelles, especially those living in slums, utilised more urban health care project facilities. The analysis found that women holding a red card in the poor strata were 6.840 times more likely to utilise delivery care at the UPHCP health facility, whereas respondents from the non-poor catchment area were only 3.499 times more likely to utilise delivery care at the UPHCP health facility. Red card holders in the project area received health care services without paying any charge and occasionally had partly subsidised services with cards. It was also found that institutional delivery was more likely to be utilised by poor strata compared to non-poor catchment areas among the richest and more by poor and nonpoor among the rich quintile. In previous studies, barriers were found in terms of time costs, travel costs, direct payments, and fear of unofficial payments in using maternity services (Miteniece et al., 2018). Thus, findings from the present study suggest that an inability to pay for services is a significant barrier in accessing childbirth care, which could be neutralised by providing red cards. In the context of universal health care, the 
entitlement approach instead of the conditional cash transfer method would be more appropriate (Ved et al., 2012). However, free drugs and transport to pregnant and postpartum women and their newborns must be assured and the pressure build-up to remove all externalities. Surprisingly, the present study found babies' high birth weight was a predictor for institutional delivery in poor strata. Previous study findings explained that more ANC visits had influence on awareness build-up regarding high risk pregnancies and pregnancy complications, which in turn influenced more women to deliver at health care institutions (Igberase et al., 2009; Zeleke et al., 2015). During ANC visits, ultrasounds are common and can estimate the baby's size. Hence, this prediction may indirectly influence pregnant mothers to have institutional deliveries (Declercq et al., 2013).

Since the data were collected up to two years after their last delivery, mothers might not recall the situation exactly. Hence, recall bias might be included in the limitation of the study.

\section{CONCLUSION}

As a whole, hospital deliveries in urban settings in Bangladesh are improving. This study revealed that in the UPHCP area, the deliveries at the UPHCP clinic were increasing and their services were mostly utilised by the poor respondents with red cardholders. Moreover, the findings of this study suggest that more awareness, public health programs, and financial subsidies or free health service program interventions will increase accessibility to the UPHCP clinic in urban slums or among the lower-income population who hesitate to deliver at a hospital due to financial barriers. Thus, safe deliveries will increase and contribute to lowering the MMR successfully to ratio targeted in the SDGs by 2030.

\section{REFERENCES}

Alkema, L., Chou, D., Hogan, D., Zhang, S., Moller, A.-B., Gemmill, A., Fat, D. M., Boerma, T., Temmerman, M., Mathers, C., \& Say, L. (2016). Global, regional, and national levels and trends in maternal mortality between 1990 and 2015, with scenario-based projections to 2030: A systematic analysis by the UN Maternal Mortality Estimation InterAgency Group. The Lancet, 387(10017), 462-474. https://doi.org/10.1016/S01406736(15)00838-7

BBS, Bangladesh. (2015). Multiple Indicator Cluster Survey 2012-2013 (p. 272). Bangladesh Bureau of Statistics (BBS) and United Nations Children's Fund (UNICEF).

Bhardwaj, N., Hasan, S. B., \& Zaheer, M. (1995). Maternal care receptivity and its relation to perinatal and neonatal mortality. A rural study. Indian Pediatrics, 32(4), 416-423.

Campbell, O., \& Graham, W. (2006). Strategies for reducing maternal mortality: Getting on with what works. Lancet, 368, 1284-1299. https://doi.org/10.1016/S01406736(06)69381-1

Declercq, E. R., Sakala, C., Corry, M. P., Applebaum, S., \& Herrlich, A. (2013). Listening to Mothers ${ }^{S M}$ III: Pregnancy and Birth. New York: Childbirth Connection, May 2013.

Eshete, T., Legesse, M., \& Ayana, M. (2019). Utilization of institutional delivery and associated factors among mothers in rural community of Pawe Woreda northwest Ethiopia, 2018. BMC Research Notes, 12(1), 395. https://doi.org/10.1186/s13104-019$\underline{4450-6}$

Filippi, V., Ronsmans, C., Campbell, O. M. R., Graham, W. J., Mills, A., Borghi, 
J., Koblinsky, M., \& Osrin, D. (2006). Maternal health in poor countries: The broader context and a call for action. Lancet (London, England), 368(9546), $1535-1541$.

https://doi.org/10.1016/S01406736(06)69384-7

Fotso, J. C., \& Mukiira, C. (2012). Perceived quality of and access to care among poor urban women in Kenya and their utilization of delivery care: Harnessing the potential of private clinics? Health Policy and Planning, 27(6), 505-515. https://doi.org/10.1093/heapol/czr07 4

Gabrysch, S., Cousens, S., Cox, J., \& Campbell, O. (2011). Distance and quality of care strongly influence choice of delivery place in rural Zambia: A study linking national data in a geographic information system. Journal of Epidemiology \& Community Health, 65(Suppl 1), A42-A42.

https://doi.org/10.1136/jech.2011.14 2976b.19

Gabrysch, Sabine, \& Campbell, O. M. (2009). Still too far to walk: Literature review of the determinants of delivery service use. BMC Pregnancy and Childbirth, $9(1), \quad 34$. https://doi.org/10.1186/1471-2393-9$\underline{34}$

Goel, M., Roy, P., Dco Dipmus, S. R., Roy, S., Kumar, Y., \& Kumar, A. (2015). Wealth index and maternal health care: Revisiting NFHS-3. Indian Journal of Public Health, 59, 217 219. https://doi.org/10.4103/0019557X.164665

HB Consultants and Natural Resources Planners. (2012). Assessing the impact of user fees on UPHCReviewing health voucher and user fees exemptions. Second Urban Primary Health Care Project,. Local
Government Division, Ministry of Local Government, Rural Development \&Cooperatives, Bangladesh.

IBM SPSS. (2013). IBM SPSS Statistics for Windows (Version 22) [Computer software]. IBM SPSS.

Igberase, G. O., Isah, E. C., \& Igbekoyi, O. F. (2009). Awareness and perception of maternal mortality among women in a semi-urban community in the Niger Delta of Nigeria. Annals of African Medicine. 8:261-5. pmid:20139550. https://doi.org/10.4103/15963519.59582

Kabia, E., Mbau, R., Oyando, R., Oduor, C., Bigogo, G., Khagayi, S., \& Barasa, E. (2019). "We are called the et cetera": Experiences of the poor with health financing reforms that target them in Kenya. International Journal for Equity in Health, 18(1), 98. https://doi.org/10.1186/s12939-0191006-2

Kitui, J., Lewis, S., \& Davey, G. (2013). Factors influencing place of delivery for women in Kenya: An analysis of the Kenya demographic and health survey, 2008/2009. BMC Pregnancy and Childbirth, 13(1), 40. https://doi.org/10.1186/1471-2393$\underline{13-40}$

Kruk, M. E., Gage, A. D., Arsenault, C., Jordan, K., Leslie, H. H., RoderDeWan, S., Adeyi, O., Barker, P., Daelmans, B., Doubova, S. V., English, M., Elorrio, E. G., Guanais, F., Gureje, O., Hirschhorn, L. R., Jiang, L., Kelley, E., Lemango, E. T., Liljestrand, J., ... Pate, M. (2018). High-quality health systems in the Sustainable Development Goals era: Time for a revolution. The Lancet Global Health, 6(11), e1196-e1252. https://doi.org/10.1016/S2214$\underline{109 X(18) 30386-3}$ 
LGRDC, Bangladesh. (2012). Design Project Proforma (DPP). Urban Primary Health Care Services Delivery Project. Ministry of Local Government, Rural development and Cooperation.

Miteniece, E., Pavlova, M., Shengelia, L., Rechel, B., \& Groot, W. (2018). Barriers to accessing adequate maternal care in Georgia: A qualitative study. BMC Health Services Research, 18(1), 631. https://doi.org/10.1186/s12913-0183432-Z

Mrisho, M., Schellenberg, J. A., Mushi, A. K., Obrist, B., Mshinda, H., Tanner, M., \& Schellenberg, D. (2007). Factors affecting home delivery in rural Tanzania. Tropical Medicine \& International Health: $T M \& I H$, 12(7), 862-872.

https://doi.org/10.1111/j.13653156.2007.01855.x

NIPORT, Bangladesh. (2013). Bangladesh Demographic and Health Survey 2011 (p. 458). National Institute of Population Research and Training Dhaka, Bangladesh Mitra and Associates Dhaka, Bangladesh MEASURE DHS ICF International Calverton, Maryland, U.S.A. https://dhsprogram.com/pubs/pdf/fr2 65/fr265.pdf

NIPORT, Bangladesh. (2016). Bangladesh Demographic and Health Survey 2014. National Institute of Population Research and Training (NIPORT), Dhaka, Bangladesh, and Rockville, Maryland, USA, Mitra and Associates, and ICF International.

Rahman, M. M. (1997). Socio-demographic determinants of infant mortality and morbidity and its correlation with maternal health in slum dwellers of Dhaka city. Dhaka University.

Rahman, M., Rob, U., Noor, F. R., \& Bellows, B. (2012). Out-of-pocket expenses for maternity care in rural Bangladesh: A public-private comparison. International Quarterly of Community Health Education, 33(2), 143-157. https://doi.org/10.2190/IQ.33.2.d

Say, L., Chou, D., Gemmill, A., Tunçalp, Ö., Moller, A.-B., Daniels, J., Gülmezoglu, A. M., Temmerman, M., \& Alkema, L. (2014). Global Causes of Maternal Death: A Who Systematic Analysis. The Lancet Global Health, 2(6), e323-e333. https://doi.org/10.1016/S2214109X(14)70227-X

Smith, V., Devane, D., Begley, C. M., \& Clarke, M. (2011). Methodology in conducting a systematic review of systematic reviews of healthcare interventions. BMC Medical Research Methodology, 11(1), 15. https://doi.org/10.1186/1471-2288$\underline{11-15}$

Stephenson, R., Baschieri, A., Clements, S., Hennink, M., \& Madise, N. (2006). Contextual influences on the use of health facilities for childbirth in Africa. American Journal of Public Health, 96(1), 84-93. https://doi.org/10.2105/AJPH.2004.0 57422

Tuladhar, H. (2009). Determinants of home delivery in a semi urban setting of Nepal. Nepal Journal of Obstetrics and Gynaecology, 4(1), 30-37. https://doi.org/10.3126/njog.v4i1.332 $\underline{9}$

Van der Heijden, J., Gray, N., Stringer, B., Rahman, A., Akhter, S., Kalon, S., Dada, M., \& Biswas, A. (2019). "Working to stay healthy", healthseeking behaviour in Bangladesh's urban slums: A qualitative study. BMC Public Health, 19(1), 600-600. PubMed.https://doi.org/10.1186/s128 89-019-6750-0 
Ved, R., Sundararaman, T., Gupta, G., \& Rana, G. (2012). Program evaluation of the Janani Suraksha Yojna. BMC Proceedings, 6(Suppl 5), O15. https://doi.org/10.1186/1753-6561-6$\underline{\mathrm{S} 5-\mathrm{O} 15}$

WHO. (2006). Integrating poverty and gender into health programmes: A sourcebook for health professionals: module on ageing. World Health Organization, Western Pacific Region.

WHO. (2015). Strategies toward ending preventable maternal mortality
(EPMM). World Health Organization Strategic Paper, 52.

WHO. (2016). Standards for improving quality of maternal and newborn care in health facilities (p. 84). World Health Organization.

Zeleke, D., Nega, A., \& Gudina, E. (2015). Maternal health care use among married women in Hossaina, Ethiopia. BMC Health Services Research.15: 365 . pmid:26358062. https://doi.org/10.1186/s12913-015$\underline{1047-1}$ 